\title{
KINH NGHIỆM XÂY DỰNG CHƯƠNG TRÌNH ĐÀO TẠO NGÀNH SƯ PHẠM LỊCH SỦ - ĐẠI HỌC THỦ DẦU MộT THEO HƯỚNG TIẾP CẬN CDIO VÀ CHUẨN AUN-QA
}

\author{
Ngô Hồng Điệp ${ }^{(*)}$ \\ (*) Tiến sĩ. Trưòng Đại học Thủ Dầu Một. Email: diepnh@tdmu.edu.vn
}

DOI: $10.37550 /$ tdmu.CFR/2021.01.139

\section{Tóm tắt}

Bắt đầu tì̀ Năm học 2014-2015, Truờng Đại học Thủ Dầu Một đã triển khai xây dụng chuơng trình đào tạo theo CDIO đồng bộ cho tất cả các nhóm ngành (trong đó có ngành Su phạm Lịch sủ, một trong nhüng ngành quan trọng của Nhà trừ̀ng). Dạy hoc theo huớng tiếp cận CDIO là một điều kiện tiên quyết để Nhà truờng đi đúng huớng trong quá trình phát triển theo đúng muc tiêu của Trưòng. Trên tinh thần tiếp cận CDIO, nhà truò̀ng và chuoong trình đào tạo (CTÐT) su phạm lịch sư lựa chọn xây dụng chuơng trình theo chuẩn AUN-QA không chi đem lại lợi ích cho nhà trường, sinh viên mà cả người sủ dụng lao động. Qua hơn 5 năm triển khai xây dựng chưong trình đào tạo Su pham Lịch sủ theo huớng tiếp cận CDIO và chuẩn $A U N-Q A$ nhà truờng đã đạt được nhũng kết quả rất đáng ghi nhận để lại nhiều kinh nghiệm quý giá trong quá trình xây dựng và phát triển CTĐT. Đặc biệt tháng 2/2020, Trung tâm Kiểm định chất lượng giáo dục-Đại học Quốc gia Hà Nội đã công nhận CTĐT Su phạm Lịch sủ là một trong bốn CTĐT của Trường đã đạt được các tiêu chí của bộ tiêu chuẩn kiểm định chất lượng CTĐT do Bộ Giáo dục và Đào tạo ban hành.

Tù̀ khóa: Chương trình đào tạo, Su phạm Lịch sủ, CDIO, AUN-QA

\section{1. Đặt vấn đề}

Qua hơn 10 năm xây dựng và phát triển, Trường Đại học Thủ Dầu Một đã khẳng định được trọng trách của mình trong chiến lược phát triển kinh tế - xã hội của đất nước. Sứ mệnh hiện nay của Nhà trường: "Là trung tâm văn hóa, giáo dục và khoa học, công nghệ. Cung cấp nguồn nhân lực, sản phẩm khoa học và công nghệ có chất luợng phục vu phát triển kinh tế xã hội và hội nhập quốc tế tỉnh Bình Dưong, miền Đông Nam Bộ và cả nước".

Trong quá trình xây dựng và phát triển, Trường Đại học Thủ Dầu Một luôn coi việc nâng cao chất lượng giáo dục và đào tạo là nhiệm vụ sống còn và cũng là trọng trách của mình trong chiến lược phát triển kinh tế - xã hội của đất nước. Quá trình xây dựng chuẩn 
đầu ra theo hướng tiếp cận $\mathrm{CDIO}$ và chuẩn $\mathrm{AUN}-\mathrm{Q} A$ cho các ngành học nói chung và ngành Lịch sử nói riêng là một trong những nỗ lực của toàn trường Đại học Thủ Dầu Một nhằm nâng cao chất lượng giáo dục và đào tạo của nhà trường. Trong phạm vi bài viết này chúng tôi đề cập đến quá trình xây dựng chương trình đào tạo ngành sư phạm lịch sử theo hướng tiếp cận $\mathrm{CDIO}$ và chuẩn $\mathrm{AUN}-\mathrm{QA}$ và những kinh nghiệm rút ra trong quá trình xây dựng và phát triển CTĐT.

\section{Nội dung}

\subsection{Sự cần thiết xây dụng chuẩn đầu ra theo hướng tiếp cận CDIO và chuẩn $A U N-Q A$}

CDIO là chữ viết tắt của mô hình Hình thành ý tưởng (Conceive) - Thiết kế (Design) Triển khai (Implement) và Vận hành (Operate). Đây là một phương pháp nhằm nâng cao chất lượng đào tạo đáp ứng yêu cầu xã hội trên cơ sở xác định chuẩn đầu ra để thiết kế chương trình và triển khai đào tạo theo một quy trình khoa học. Từ thực tiễn áp dụng CDIO ở hơn 100 trường Đại học trên thế giới và các trường Đại học ở Việt Nam, Trường Đại học Thủ Dầu Một đã mạnh dạn áp dụng xây dựng chương trình đào tạo cho các ngành theo hướng tiếp cận CDIO.

Khung đảm bảo chất lượng AUN-QA (ASEAN University Network - Quality Assurance) được xây dựng nhằm giúp cải tiến chất lượng giáo dục trong khu vực, hỗ trợ sự lưu động của người học, người lao đông và chuyên gia giữa các quốc gia trong khu vực và với quốc tế. Bộ khung được nghiên cứu, xây dựng và cải tiến để đảm bảo các quốc gia có thể áp dụng trong những bối cảnh chính trị, văn hóa và pháp luật khác nhau mà không ảnh hưởng đến những giá trị và truyền thống cốt lõi của từng quốc gia.

Đối với từng ngành, từng môn học, phương pháp tiếp cận $\mathrm{CDIO}$ và chuẩn $\mathrm{AUN}-\mathrm{QA}$ đã gợi ý những luận điểm quan trọng trong đổi mới cách xác định chuẩn đầu ra (CĐR), xây dựng nội dung chương trình và đổi mới phương pháp dạy học nhằm nâng cao chất lượng đào tạo theo hướng đáp ứng nhu cầu xã hội. Chương trình đào tạo Cử nhân lịch sử là chương trình đào tạo đòi hỏi người được đào tạo sau khi tốt nghiệp đảm bảo đủ trình độ nghiệp vụ và chuyên môn nghề nghiệp (lí thuyết và thực hành) để áp dụng vào thực tế công việc. Một cử nhân sử học cần phải có những năng lực toàn diện, có đủ trình độ chuyên môn nghề nghiệp để phục vụ đắc lực cho sự nghiệp phát triển đất nước bao gồm tri thức, kĩ năng chuyên môn đồng thời phát triển năng lực phương pháp, năng lực xã hội và năng lực cá thể. Đề xướng $\mathrm{CDIO}$ và chuẩn $\mathrm{AUN}-\mathrm{Q} A$ nhằm cải cách toàn diện hoạt động đào tạo cử nhân lịch sử trong bối cảnh nghề nghiệp và xã hội là một sự phù hợp tất yếu.

Ở góc độ lí luận dạy học, chúng ta tiếp cận CDIO và chuẩn AUN-QA để đề xuất một phương pháp, làm cơ sở lí thuyết cho việc vận dụng linh hoạt các luận điểm cơ bản của CDIO vào thực tiễn đào tạo các ngành nghề đảm bảo nâng cao được chất lượng dạy học đáp ứng nhu cầu xã hội. Theo chủ trương của Nhà trường, cách làm này không phải là phủ nhận hoàn toàn các phương pháp truyền thống, không phá vỡ cấu trúc hệ thống mà chúng ta sẽ phát triển các thành tố trong cấu trúc đó theo triết lí của phương pháp tiếp cận CDIO, chuẩn AUN-QA và của lí luận dạy học hiện đại, mô tả những thành tố đó một cách cụ thể 
để có thể vận dụng dễ dàng trong vai trò của một người giảng viên khi thiết kế và thực hiện bài học.

Mô hình giảng dạy theo tiếp cận CDIO và chuẩn $A U N-Q A$ phải giúp cho giảng viên tuân thủ các chuẩn mực về thiết kế dạy học và chuyển tải $\mathrm{C} Đ \mathrm{R}$ của chương trình trong từng bài giảng, từng hoạt động dạy học, với quy trình cụ thể đảm bảo việc thực hiện diễn ra thuận lợi, hiệu quả và phù hợp với điều kiện thực tiễn ở nước ta. Nguyên tắc này đòi hỏi toàn thể cán bộ giảng viên phải xem việc tiếp cận $\mathrm{CDIO}$ và chuẩn $\mathrm{AUN}-\mathrm{QA}$ phải là một giải pháp hữu hiệu để nâng cao chất lượng đào tạo. Các giảng viên phải nhìn nhận toàn diện hơn về phương pháp giảng dạy và học tập cũng như cách đánh giá sinh viên.

Việc đào tạo cử nhân Sư phạm Lịch sử theo hướng tiếp cận CDIO và chuẩn AUN-QA sẽ gắn kết được cơ sở đào tạo với yêu cầu của người tuyển dụng, từ đó thu hẹp khoảng cách giữa đào tạo của nhà trường và yêu cầu của nhà sử dụng nguồn nhân lực; Giúp người học phát triển toàn diện với các kĩ năng cứng và kĩ năng mềm để nhanh chóng thích ứng với môi trường làm việc luôn thay đổi và thậm chí là đi đầu trong việc thay đổi đó; Giúp môn học và chương trình đào tạo được xây dựng và thiết kế theo một quy trình chuẩn; Các công đoạn quá trình đào tạo có tính liên thông và gắn kết khoa học chặt chẽ...

\subsection{Thực trạng xây dụng chuẩn đầu ra theo hướng tiếp cận CDIO và chuẩn $A U N$ - QA ngành sư phạm lịch sü̉}

Bắt đầu từ năm học 2014-2015, Trường Đại học Thủ Dầu Một đã bắt đầu triển khai xây dựng chương trình đào tạo theo $\mathrm{CDIO}$ và chuẩn $\mathrm{AUN}-\mathrm{QA}$ đồng bộ cho tất cả các nhóm ngành. Lãnh đạo Nhà trường luôn quan tâm tạo điều kiện để giảng viên cập nhật kiến thức và thông tin hữu ích về các giải pháp mới, góp phần xây dựng chương trình đào tạo đáp ứng nhu cầu đào tạo chất lượng cao, thích nghi với thực tiễn của thị trường lao động.

Ngành Sư phạm Lịch sử là một trong số các ngành quan trọng của Nhà trường được đầu tư xây dựng chương trình chuẩn đầu ra theo hướng tiếp cận CDIO và chuẩn AUN-QA.

Trong quá trình xây dựng chương trình chuẩn đầu ra theo hướng tiếp cận $\mathrm{CDIO}$ và chuẩn AUN-QA đối với ngành Sư phạm Lịch sử luôn nhận được sự quan tâm của nhà trường với những chính sách phù hợp tạo cơ chế thuận lợi cho công tác triển khai. Nhà trường đã mời các chuyên gia tập huấn mô hình đào tạo $\mathrm{CDIO}$ và chuẩn $\mathrm{AUN}-\mathrm{QA}$ cho toàn thể giảng viên. Sau đợt tập huấn, Khoa và các bộ môn tập trung xây dựng chương trình cho phù hợp với ngành, bộ môn của mình. Cụ thể, ngành sư phạm lịch sử đã rà soát lại toàn bộ chương trình, xây dựng lại chuẩn đầu ra cho ngành và chuẩn đầu ra cho từng môn học và từ chuẩn đầu ra này, khoa sẽ thiết kế lại chương trình đào tạo cho phù hợp với hệ thống các mục tiêu giáo dục gồm các tiêu chuẩn và tiêu chí đề cập đến triết lý chương trình, chuẩn đầu ra, chương trình đào tạo tích hợp, không gian học, đánh giá học tập....của CDIO và chuẩn AUN-QA. Đây là một bước đột phá trong việc xây dựng chương trình đào tạo đồng thời đổi mới phương pháp giảng dạy và nâng cao năng lực giảng dạy của giảng viên.

Theo chương trình chuẩn đầu ra theo hướng tiếp cận $\mathrm{CDIO}$ và chuẩn $\mathrm{AUN}-\mathrm{QA}$, sinh viên ngành Sư phạm Lịch sử sẽ được trang bị nhiều kiến thức và kỹ năng đáp ứng yêu cầu thời kỳ hội nhập. Bởi vì, với chuẩn đầu ra theo hướng tiếp cận CDIO và chuẩn AUN-QA thì kiến thức không thay đổi nhiều lắm nhưng sinh viên sẽ học thêm nhiều về kỹ năng, thái độ. Hai môn học 
này tích hợp vào đó kỹ năng cho sinh viên như soạn thảo văn bản hành chính, tìm kiếm thông tin trên Internet, trình bày trước đám đông, đọc hiểu và giải quyết vấn đề. Sinh viên cũng được nói về sự trung thực, tuân thủ quy định, cam kết khi nhận công việc...

Theo cách tiếp cận CDIO và chuẩn $\mathrm{AUN}-\mathrm{Q} A$, khi xây dựng và nâng cấp các chương trình đào tạo phải tuân thủ các quy trình chặt chẽ, từ khâu xây dựng $C Đ R$, thiết kế khung chương trình, chuyển tải khung chương trình vào thực tiễn và đánh giá kết quả học tập của sinh viên cũng như toàn bộ Chương trình.

Qua hơn 5 năm triển khai xây dựng chương trình đào tạo sư phạm lịch sử theo hướng tiếp cận CDIO và chuẩn AUN-QA nhà trường đã đạt được những kết quả rất đáng ghi nhận. Đặc biệt tháng 2/2020, Trung tâm Kiểm định chất lượng giáo dục - Đại học Quốc gia Hà Nội đã công nhận CTĐT sư phạm lịch sử là một trong bốn CTĐT của Trường đã đạt được các tiêu chí của bộ tiêu chuẩn kiểm định chất lượng CTĐT do Bộ Giáo dục và Đào tạo ban hành.

Ngành Sư phạm Lịch sử cũng là một trong những ngành tiên phong của đại học Thủ Dầu Một trong việc đào tạo trình độ thạc sĩ và tiến sĩ. Trong quá trình xây dựng chuẩn đầu ra theo hướng tiếp cận $\mathrm{CDIO}$ và chuẩn $\mathrm{AUN}-\mathrm{QA}$, nhà trường cũng đã quan tâm xây dựng chuẩn đầu ra theo hướng tiếp cận $\mathrm{CDIO}$ và chuẩn $\mathrm{AUN}-\mathrm{QA}$ cho chương trình đạo tạo cao học và nghiên cứu sinh ngành lịch sử Việt Nam. Đây là một bước đi đúng đắn thể hiện tầm nhìn của lãnh đạo nhà trường và sức bật của một trường đại học đang phát triển mạnh mẽ theo hướng đa ngành.

\section{Một số kinh nghiệm rút ra trong qua trình xây dụng chương trình đào tạo}

Việc lựa chọn xây dựng chương trình đào tạo hướng tiếp cận $\mathrm{CDIO}$ và chuẩn $\mathrm{AUN}$ QA ngành sư phạm lịch sử của trường đại học Thủ Dầu Một không chỉ đem lại lợi ích cho nhà trường, sinh viên mà cả người sử dụng lao động.

Việc tiếp cận theo phương pháp CDIO và chuẩn AUN-QA sẽ đem lại các lợi ích sau:

- Đào tạo gắn với nhu cầu của người tuyển dụng, từ đó giúp thu hẹp khoảng cách giữa đào tạo của nhà trường và yêu cầu của nhà sử dụng nguồn nhân lực;

- Giúp người học phát triển toàn diện với các "kỹ năng cứng" và "kỹ năng mềm" để nhanh chóng thích ứng với môi trường làm việc luôn thay đổi;

- Chương trình đào tạo được xây dựng và thiết kế theo một quy trình chuẩn. Các công đoạn của quá trình đào tạo sẽ có tính liên thông và gắn kết chặt chẽ;

- Cách tiếp cận CDIO và chuẩn $\mathrm{AUN}-\mathrm{Q} A$ là cách tiếp cận phát triển, gắn phát triển chương trình với chuyển tải và đánh giá hiệu quả giáo dục đại học, góp phần nâng cao chất lượng giáo dục đại học lên một tầm cao mới.

Sinh viên trong chương trình đào tạo theo CDIO và chuẩn AUN-QA sau khi tốt nghiệp sẽ đạt được bốn năng lực chính, bao gồm: khối kiến thức và lập luận ngành; các kỹ năng và phẩm chất cá nhân về nghề nghiệp; các kỹ năng và phẩm chất xã hội; năng lực áp dụng kiến thức vào thực tiễn đặt trong bối cảnh xã hội và các đơn vị sử dụng lao động. 
Từ thực tiễn cho thấy rằng giảng viên dạy theo chương trình $\mathrm{CDIO}$ và chuẩn $\mathrm{AUN}$ QA nhiệt tình trong công tác giảng dạy, kỹ năng sư phạm tốt, sinh viên được hướng dẫn và tổ chức làm việc nhóm tốt, thắc mắc của sinh viên được giảng viên giải đáp rõ ràng, các môn học giúp sinh viên tăng sự chủ động trong việc học tập.

Quá trình xậy dựng, vận hành CTĐT, vượt qua những khó khăn, thách thức cũng để lại những bài học kinh nghiệm quý cho công tác đào tạo.

Qua nhiều năm triển khai chuẩn đầu ra theo hướng tiếp cận CDIO và chuẩn AUN-QA ngành Sư phạm Lịch sử nói riêng và các ngành nói chung, Lãnh đạo Nhà trường đã nhìn nhận những khó khăn, trở ngại trong quá trình thí điểm thực hiện $\mathrm{CDIO}$ và chuẩn $\mathrm{AUN}$ QA. Khó khăn lớn nhất trong quá trình triển khai là yếu tố con người. Cụ thể như việc giảng viên chịu áp lực rất lớn về thời gian để chuẩn bị và giảng dạy theo phương pháp mới mà hiện nay đội ngũ giảng viên, nhân viên Nhà trường chưa có nhiều kinh nghiệm với yêu cầu đào tạo của chương trình. Mặt khác, nguồn kinh phí đầu tư cơ sở vật chất khi áp dụng CDIO và chuẩn $A U N-Q A$ khá cao... Nhưng vượt lên tất cả là tinh thần sáng tạo, tư duy đổi mới và sự đồng long thống nhất của cả hệ thống trong nhà trường đã giúp nhà trường vượt qua những trở ngại và đạt được mục tiêu đề ra.

Trong hơn 5 năm qua, cùng với việc triển khai mô hình $\mathrm{CDIO}$ và chuẩn $\mathrm{AUN}-\mathrm{QA}$ trong toàn trường, việc xây dựng chuẩn đầu ra theo hướng tiếp cận CDIO và chuẩn AUNQA đối với ngành Sư phạm Lịch sử đã được thực hiện một cách đồng bộ và đúng theo kế hoạch của nhà trường.

Trong quá trình triển khai, đại học Thủ Dầu Một luôn tranh thủ học hỏi kinh nghiệm từ các trường trong nước và quốc tế để có bước đi thật vững chắc.

Mặc dù mới triển khai trong một thời gian chưa nhiều, nhưng những kết quả đạt được ban đầu là rất đáng ghi nhận. Trên cơ sở nhìn nhận những thuận lợi và khó khăn, theo chúng tôi trong thời gian tiếp theo để xây dựng chuẩn đầu ra theo hướng tiếp cận $\mathrm{CDIO}$ và chuẩn AUN-QA ngành lịch sử nói riêng và các ngành nói chung cần tập trung vào các giải pháp sau đây:

Một là, nhà trường tiếp tục triển khai các chương trình tập huấn CDIO và chuẩn AUN-QA cho đội ngũ giảng viên, cán bộ thiết kế chương trình và tổ chức các chương trình tọa đàm chuyên sâu về $\mathrm{CDIO}$ và chuẩn $\mathrm{AUN}-\mathrm{QA}$.

Hai là, các đơn vị trong trường cùng nhau chia sẻ các nội dung về yêu cầu đối với chương trình đào tạo, hướng dẫn thiết kế và phát triển chương trình theo phương pháp tiếp cận $\mathrm{CDIO}$ và chuẩn $\mathrm{AUN}-\mathrm{Q} A$; hướng dẫn thiết kế đề cương môn học và xây dựng chuẩn đầu ra, chương trình đào tạo tích hợp theo CDIO và chuẩn AUN-QA. Với các hoạt động này, $\mathrm{CDIO}$ và chuẩn $\mathrm{AUN}-\mathrm{QA}$ sẽ được lan tỏa ở tất cả các khối ngành của đại học Thủ Dầu Một, dần giúp thói quen học thụ động của sinh viên được thay thế bằng sự chủ động trong học tập và đầy tính sáng tạo, gợi mở từ chính người giảng viên của mình, giúp sinh viên có các kỹ năng tốt hơn trong cuộc sống.

Ba là, nhà trường tiếp tục đẩy mạnh việc sử dụng phương pháp tiếp cận toàn diện, có hệ thống của $\mathrm{CDIO}$ và chuẩn $\mathrm{AUN}-\mathrm{QA}$ để cải tiến chương trình đào tạo, cung cấp kỹ năng thiết kế - triển khai chương trình. Cụ thể, Trường sẽ đẩy mạnh việc nâng cao năng lực giảng 
viên để chuẩn bị những nguồn lực thiết yếu, trang bị cơ sở vật chất phục vụ hiệu quả cho hoạt động triển khai $\mathrm{CDIO}$ và chuẩn $\mathrm{AUN}-\mathrm{QA}$.

Bốn là, dù đã đạt được chuẩn kiểm định chất lượng CTĐT do Bộ Giáo dục và Đào tạo ban hành nhưng nhà trường luôn duy trì hoạt động kiểm định chất lượng giáo dục là công tác được thực hiện thường xuyên, nhằm không ngừng cải tiến, nâng cao chất lượng đào tạo, thương hiệu giáo dục của nhà Trường.

\section{Kết luận}

Sau hơn 5 năm thực hiện xây dựng chương trình đào tạo theo hướng tiếp cận CDIO và chuẩn AUN-QA, đại học Thủ Dầu Một đã có những đổi mới căn bản về cách thức tổ chức chương trình, năng lực giảng viên, phương pháp giảng dạy giúp phát triển toàn diện kiến thức, kỹ năng, phẩm chất và năng lực thực hành nghề nghiệp cần thiết cho sinh viên,... Minh chứng rõ ràng nhất là việc Trung tâm Kiểm định chất lượng giáo dục - Đại học Quốc gia Hà Nội đã công nhận CTĐT sư phạm lịch sử là một trong bốn CTĐT của Trường đã đạt được các tiêu chí của bộ tiêu chuẩn kiểm định chất lượng CTĐT do Bộ Giáo dục và Đào tạo ban hành.

Việc xây dựng và phát triển CTĐT theo hướng tiếp cận $\mathrm{CDIO}$ và chuẩn AUN-QA là biện pháp tối ưu để khẳng định chất lượng của nhà trường với người học và toàn xã hội. Qua hơn 5 năm triển khai xây dựng chương trình đào tạo sư phạm lịch sử theo hướng tiếp cận $\mathrm{CDIO}$ và chuẩn $\mathrm{AUN}-\mathrm{QA}$ nhà trường đã đạt được những kết quả rất đáng ghi nhận để lại nhiều kinh nghiệm quý giá trong quá trình xây dựng và phát triển CTĐT.

Việc xây dựng và phát triển CTĐT theo hướng tiếp cận CDIO và chuẩn AUN-QA thể hiện quyết tâm của Trường Đại học Thủ Dầu Một trong việc nâng cao chất lượng giảng dạy, xây dựng thương hiệu uy tín, cạnh tranh, nhằm tạo ra một thế hệ sinh viên bản lĩnh, tự tin và đáp ứng được nhu cầu của xã hội. Đây là bước khởi đầu quan trọng trong lộ trình dài phía trước, đòi hỏi sự đồng tâm hiệp lực của toàn thể đội ngũ cán bộ giảng viên, nhân viên và sinh viên Nhà trường để đạt được mục tiêu chiến lược trở thành trường đại học thông minh có uy tín trong nước và quốc tế, vào tốp 200 đại học tốt nhất Châu Á.

\section{Tài liệu tham khảo}

[1] Đại học Quốc gia thành phố Hồ Chí Minh (2012), Đào tạo đáp ứng nhu cầu xã hội và hội nhập quốc tế, Hội nghị CDIO toàn quốc.

[2] Đại học quốc gia TP.HCM (2016), Tài liệu hướng dẫn Tài liệu hướng dẫn đánh giá chất lượng cấp chương trình theo tiêu chuẩn AUN - QA (phiên bản 3.0), Nxb ĐHQG-HCM.

[3] Hồ Tấn Nhựt, Đoàn Thị Minh Trinh (2009), Cải cách và xây dưng chuoơng trình đào tạo kỹ thuật theo phuong pháp tiếp cận CDIO, Nxb Đại học Quốc gia TP.HCM.

[4] Ban biên tập Trang thông tin điện tử - Đại học Thủ Dầu Một, Chiến lược phát triển Đại học Thủ Dầu Một đến năm 2030, https://www.tdmu.edu.vn/tin-tuc/tin-tong-hop/chien-luoc-phat-triendai-hoc-thu-dau-mot-den-nam-2030, ngày truy cập 03/03/2019. 
[5] Trường Đại học Thủ Dầu Một (2018), Kế hoạch chiến lược đảm bảo chất lượng của trường Đại học Thủ Dầu Một (giai đoạn 2018 - 2020, tầm nhìn 2030), ngày 27/09/2018. 